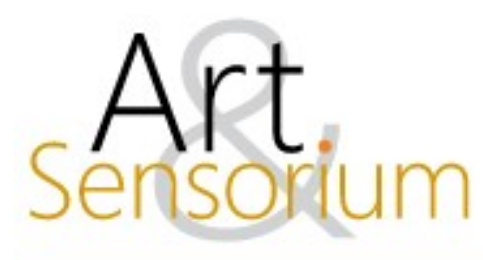

\title{
AGULHA, FURO, LINHA: DOS PONTOS AO NÓ NOS DEBAIXOS DA EDUCAÇÃO SEXUAL FEMININA
}

\author{
DOI: https://doi.org/10.33871/23580437.2020.7.2.313-330
}

Kellyn Batistela ${ }^{1}$

\begin{abstract}
Resumo: As ações do bordar acionam pensamento crítico nos espaços de resistência da arte contemporânea. É nessa matriz de engajamento de subjetividades críticas femininas, à contrapelo de uma epistemologia normativa, que minha prática artística investiga o não-dito e o irrepresentável da educação sexual feminina, diante da retórica scientia sexualis do século XIX ainda visível em 1960 e 1970 em publicações no Brasil. A intenção é a de construir um percurso arqueográfico, pela linguagem do bordado e da fotomontagem, capaz de rastrear nos debaixos da experiência feminina (os panos e manchas que encobrem a intimidade) - ligados à herança enciclopédica - discursos sobre a educação da sexualidade e do prazer femininos postos em silêncio e coibidos.
\end{abstract}

Palavras-chave: Arte contemporânea; Educação feminina; Scientia sexualis; Grafia do bordado; Subjétil

\section{NEEDLE, HOLE, LINE: FROM POINTS TO KNOTS UNDER FEMALE SEXUAL EDUCATION}

\begin{abstract}
The actions of embroidery trigger critical thinking in the spaces of resistance of contemporary art. It is in this matrix of engagement of critical female subjectivities, as opposed to a normative epistemology, that I investigate the unsaid and the unrepresentable about female sexual education. The 19th century scientia sexualis rhetoric is still visible in 1960 and 1970 in publications in Brazil. The intention is to build an archaeological path, through the language of embroidery and photomontage, capable of tracking discourses on the education off emale sexuality and pleasure, silenced and restrained.
\end{abstract}

Keywords: Contemporary art; Female education; Scientia sexualis; Embroidery spelling; Subjétil

\footnotetext{
${ }^{1}$ Doutoranda em Artes Visuais, Processos Artísticos (PPGAV/CEART), pela Universidade do Estado de Santa Catarina (UDESC), pesquisadora e bolsista FAPESC. Mestre em Teoria Literária pela Universidade Federal de Santa Catarina (UFSC). Integrante do projeto de pesquisa "Políticas e poéticas da arte africana contemporânea no contexto da globalização", (UDESC). Desenvolve prática artística relacionada à arte feminina, arte de arquivo, escrita de si. Link para Lattes: http://lattes.cnpq.br/5882375152066947. ORCID: http://orcid.org/0000-0002-7332-241X. kellynbatistela@gmail.com
} 


\section{AGUJA, AGUJERO, LÍNEA: DE PUNTOS A NUDOS BAJO LA EDUCACIÓN SEXUAL FEMENINA}

Resumen: Las acciones del bordado desencadenan el pensamento crítico en los espacios de resistência del arte contemporáneo. Es en esta matriz de compromiso de subjetividades femeninas críticas, en oposición a una epistemología normativa, donde investigo lo no dicho y lo no representable sobre la educación sexual femenina. La retórica de la scientia sexualis del siglo xix todavía es visible en 1960 y 1970 en publicaciones en brasil. La intención es construir un caminho arqueológico, a través del linguaje del bordado y el fotomontaje, capaz de rastrear discursos sobre la educación dela sexualidad y el placer feminino, silenciados y restringidos.

Palabras clave: Arte Contemporaneo; Educación femenina; Scientia sexualis; Ortografía de bordado; Subjétil

\section{Questão posta, a enciclopédia e o livro de bordado}

Partindo da leitura crítica de algumas pedagogias normativas sobre a educação sexual feminina, investigo - através de fatura artística aqui apresentada por bordados e fotomontagens, intituladas Lições enciclopédicas e Roupa de baixo - o entrecruzamento do livro de bordado com a enciclopédia sexual, ambos destinados à cultura educativa do feminino. É no quarto das mulheres, como descreve Michelle Perrot, que elas viveram, trabalharam, leram suas cartas de amor, devoraram livros, instruíram-se, bordaram, costuraram e sonharam. "O quarto seria por excelência o lugar das mulheres, seu tabernáculo. Tudo concorre para encerrá-las aí: a religião, a ordem doméstica, a moral, a decência, o pudor, mas também o imaginário erótico, que senta as mulheres sonhadoras à janela ou as reclina, leitoras lânguidas, mais ou menos despidas, sobre um sofá, um canapé ou uma cama" (2011, p. 131).

Sobre o livro de bordados, é no ano de 1905 que a Singer Corporation obtém o registro para operar no Brasil, e com isso, a máquina de bordar passa a modernizar a secular arte das práticas manuais e a inserir-se no espaço doméstico como signo utilitário do mobiliário moderno. É curioso notar que junto ao objeto de prestigio segue-se a edição colorida, impressa em tipografia, do manual instrutivo cujos direitos autorais, em 1933, asseguravam-se pela Escola Nacional de Belas Artes. Esses livros, didaticamente ilustrados, com esquemas que possibilitavam o aprendizado autônomo, foram editados pela Singer Corporation com a intenção de aproximar as usuárias do artefato industrial, alfabetizando gerações de mulheres brasileiras às lições do bordado à máquina. Reuniam o aprendizado sistematizado que iam do manejo com as fazendas às tensões, das linhas e agulhas à tipologia dos pontos, e portanto, configuravam uma pequena enciclopédia ou inventário taxionômico sobre os elementos de armarinho e auxiliavam, também, o desenvolvimento das usuais práticas artísticas domésticas, necessárias à educação de futuras esposas.

Em uma das regras do pesponto em crivos, o manual atenta aos cuidados da aprendiz com a prática do bordado na exata combinação entre tipo do ponto, tamanho da agulha e composição das linhas:

é necessário que a aluna observe estritamente tudo o que é estabelecido na "Tabela de Pontos" que se reproduz, onde se especificam os tamanhos das agulhas e a quantidade de pontos que se deve dar por centímetro em cada uma das combinações de linhas de bordar, linhas de costurar ou sêda. Na Tabela estão incluídas ùnicamente as de uso mais comum para a confecção de bordados e encaixes. Se não fôr observado o indicado na Tabela e si se derem menos pontos por centímetro que os indicados, notar-se-á a união das linhas, o que é um defeito; se pelo contrário, se 
derem mais pontos, os pespontos deformar-se-ão ao ser retirado o trabalho do bastidor (LIVRO DE BORDADOS SINGER, 1947, pp. 9-10). ${ }^{2}$

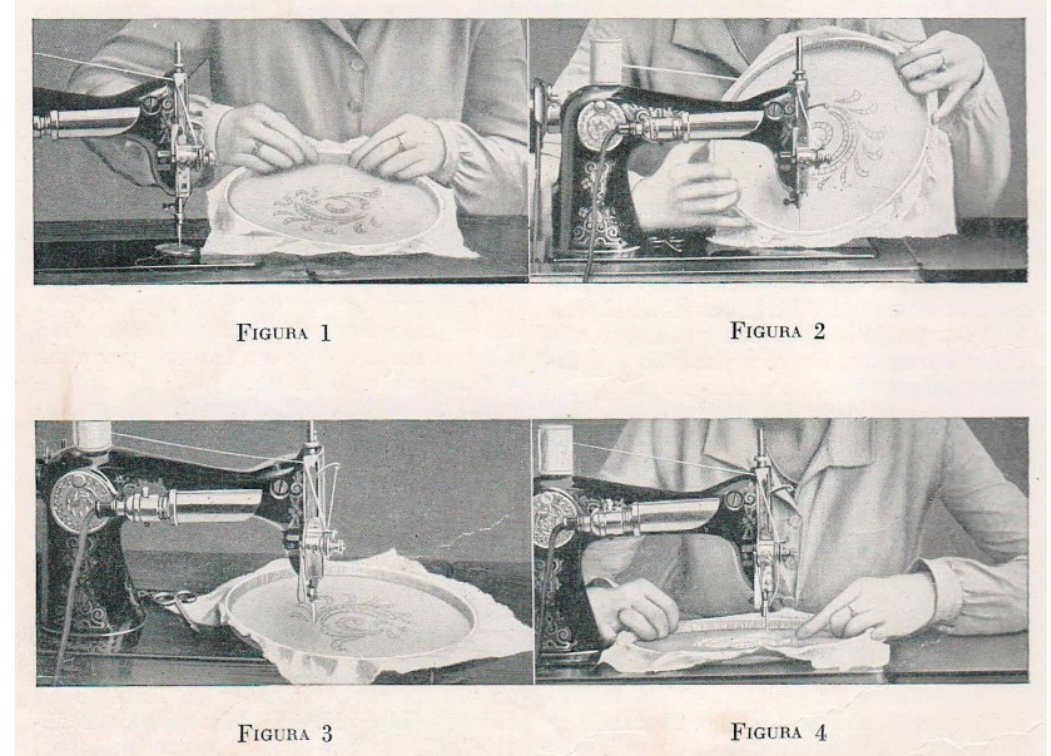

Figura 1: "Preparação do trabalho", Livro de bordados Singer, 1947, p. 8. FONTE: Da autora

Segundo as indicações do livro de bordado, a "preparação do trabalho", ilustração do bordado Richelieu, resumia-se em mover o bastidor durante o tempo em que a agulha não atravessa o tecido e a fazer com que a atravesse no ponto em que se deseja. Uma prática disciplinada de coordenação entre mãos no bastidor e pés sobre o pedal: "para conseguir uma marcha lenta, muito necessária ao trabalho de bordado, deve-se oprimir levemente o pedal, primeiro com um pé e depois com o outro, iniciando o movimento com um ligeiro impulso para diante, que se deve dar, fazendo girar, com a mão direita, o volante da máquina" (Livro de bordados Singer, 1947, p. 5).

Se de um lado, a educação feminina correspondia, no Brasil da segunda metade do século XX, aos belos feitos domésticos, também se pode entrever nas entrelinhas desse modus operandi do bordado a prescrição do moderado temperamento feminino nas relações conjugais. De outro lado, quando a sexualidade feminina é posta em silêncio e sob vigilância doméstica, o permitido destinava-se à leitura das enciclopédias ilustradas. Esse é o caso da Enciclopédia Ilustrada da Vida Sexual ${ }^{3}$, de

\footnotetext{
${ }^{2}$ Mantém-se, ao citar o texto do Livro de Bordado Singer e da Enciclopédia da vida sexual de Magnus Hirschfeld, o código de acentuação ortográfica original de sua publicação no Brasil. Nesse ato, reconheço a história da língua, ou seja, sua memória temporalmente gráfica e sistêmica. Adaptar o texto ao código vigente seria obliterar as suas idiossincrasias, pois a linguagem também é matéria textual que se adapta às exigências canônicas dos sistemas de representação.

${ }^{3}$ A Enciclopédia Ilustrada da Vida Sexual de Magnus Hirschfeld foi publicada no Brasil, por Edições Spiker, na cidade do Rio de Janeiro. A versão que é tomada por referência nesse texto é a $4^{a}$. edição aumentada, em impressão tipográfica, possivelmente datada da década de 1960, hipótese lançada pela análise do código ortográfico presente na escrita que assinala o uso do acento circunflexo aos pronomes [êle, êste, êsta, êsse, êssa], [daquêles, dêsse, aquêle], [sôbre], aos substantivos [bôlsa], [ôvo], [nôvo], [ôco], [pêra], [flôres], [êrro], [acôrdo], [mêdo], [fôrça], aos adjetivos [espêsso], [tôda] aos advérbios [vêzes]; uso do acento grave para [fàcilmente], [sòmente], [sòzinho], [invariàvelmente], acentuação gráfica em voga até 1971.
} 
Magnus Hirschfeld ${ }^{4}$, traduzida e publicada no Brasil, em quarta edição ampliada, em meados da década de 1960, que se destina a

(...) diz respeito ao homem como à mulher. Tanto a parte fisiológica, como a decorrência da mesma na vida do homem e da mulher, seja no sentido puramente físico, como no amoroso. A vida sexual não deve ser olhada sòmente como o contacto entre o homem e a mulher, pois sendo êsse um ponto altamente social, deve ser estudado em seus múltiplos aspectos, no sentido de ser achado o colorário que, indiscutivelmente, será a felicidade daquêles que se amam. É verdade que o homem jamais se livrará dos conflitos que o levam a um viver desordenado e em desacôrdo com os verdadeiros princípios da natureza. Também êsses pontos são estudados nesta obra, tendo em vista a possível solução de casos que conduzem o homem a situações que constituem verdadeiros cáos. $\mathrm{O}$ que resulta dos nossos estudos é o dever que a tôdos nós cabe de corrigir as nossas deficiências, para que possamos defender a harmonia da nossa vida conjugal, pois que sòmente nela repousa a estabilidade do lar e a verdadeira felicidade da família. Conforme diz o título da nossa obra, tudo quanto respeita ao problema sexual seja na sua parte física, social ou psicológica, acha-se detidamente estudado, motivo pelo qual estamos certos das grandes vantagens que da sua leitura advirão para os seus leitores (HIRSCHFELD, s/d, p. 5).

Sobrepor o antigo Livro de Bordados Singer à Enciclopédia Ilustrada da Vida Sexual é potência de desmonte que ativa - nas sobrevidas críticas das práticas domésticas femininas, retomadas por artistas mulheres - os sintomas historicamente negligenciados pela representação científica da natureza da mulher, esta que sempre teve sua sexualidade definida pela diferença entre os sexos cujo padrão sempre fora o do homem. Portanto, a postura detetivesca assumida nesse texto, juntamente com o conjunto de trabalhos da prática artística, entrecruza essas duas sintaxes ilustrativas, o livro de bordado e sua tékhne ( $\varepsilon \dot{\chi} \chi \vee \eta)$ e os diagramas ilustrados da enciclopédia e sua suposta scientia sexualis. Os entraves determinados pela scientia sexualis, advindos do século XIX, orientou um regime de verdades enciclopedista, de urgência biológica e histórica, que averbou o sistema sexo/gênero como produção disciplinar da sexualidade. No presente texto constam duas séries de trabalhos de minha prática artística, Roupa de baixo e Lições enciclopédicas. Muito embora destoam na linguagem estética de suas sintaxes visuais, uma por ser apropriação de imagem e ter a fotomontagem como técnica, a outra, que também se vale da apropriação do enxoval bordado maternal, enuncia-se pelo desenho em grafite, tão próprio das ilustrações enciclopédicas.

Roupa de Baixo é uma paródia cuja técnica da montagem vale-se da apropriação de campanhas publicitárias de modeladores e sutiãs (das marcas De Millus, Rhodianyl e Lycra veiculados na revista JOIA entre os anos de 1968 e 1969 e na revista DESFILE entre os anos de 1970 a 1972) e de modernos artefatos e cosméticos destinados aos cuidados femininos. Esses anúncios reafirmaram a soberania das práticas discursivas e disciplinares heteronormativas através da scientia sexualis. Essa sofisticada "cosmética sexual" (de representação entre referência e referente, entre natureza e artifício, entre sexo e gênero) explora a diferença sexual como heterodivisão. Pelas constantes repetições os códigos naturalizados reafirmam narrativas visuais da produção-reprodução,

\footnotetext{
${ }^{4}$ Sobre o autor, Magnus Hirschfeld (1868-1935), médico e sexólogo alemão que em 1897, juntamente com Eduard Oberg, Max Spohr e Franz Josef von Bülow, fundou o Wissenschaftlich-humanitäres Komitee (Comité CientíficoHumanitário). Foi o primeiro diretor do Instituto da Ciência da Sexualidade (Institut für Sexualwissenschaft) que advogava em nome de pesquisas científicas sobre sexo, psicologia e etnologia, incluindo consultas de aconselhamento matrimonial e sexual. Magnus Hirschfeld é considerado o pioneiro nas causas homossexuais que o levou em 1928 à formação da Liga mundial para a reforma sexual na Alemanha, e portanto, foi defensor da revogação do parágrafo 175 da constituição que penalizava as relações homossexuais.
} 
"qualificando um corpo para a vida dentro do domínio da inteligibilidade cultural" (BUTLER, 2019, p. 17).

Lições enciclopédicas partem do conceito de escrita de si, com o qual problematizo a constituição do sujeito feminino, no jogo da verdade, quando se revisam as práticas disciplinares sobre a educação sexual feminina no normativo espaço doméstico. Nesse sentido, o bordado é entendido como um dispositivo à grafia de si e um gatilho crítico às práticas de educação doméstica. Não há ponto bordado sem o furo, essa prática da grafia do ornato, como escrita de si, tensiona o regime de verdades enciclopédicas herdadas das práticas disciplinares. Meu interesse reside em detectar uma via de transmissão oral que testemunho ser silenciosa a respeito da experiência da educação sexual feminina, enunciada através do aprendizado doméstico na relação entre mãe e filha. Decorre que muito além de ser uma narrativa de si e sobre si, é uma constituição de si a partir da coleta do dizer das outras, uma subjetivação da experiência sexual do feminino pela partilha polifônica. A micro prática da pesquisa plástica, sobre a educação sexual feminina, está em recolher/acolher as sobras do sabonete feminino de um grupo de mulheres que mobilizam saberes orais: aqueles sussurros que outrora foram narrados clandestinamente entre dobras e pontos invisíveis na feitura dos enxovais ou aqueles bordados em que nunca se permitiram o ponto final em relacionamentos de opressão. Acionar a fala franca é tentar ativar a anamnese da experiência entre mãe e filha, já que é através da matriz maternal e, supostamente afetiva, que se transmitem as normativas de educação sexual feminina ou as primeiras impressões sobre a intimidade sexual.

\section{O livro que despe cientificamente o corpo}

As práticas domésticas sempre acompanharam o feminino e a ele se impuseram pelas pedagogias comportamentais que ditaram normas de boas maneiras, conduta, responsabilidades, tudo se reportando ao defloramento da sexualidade que deveria ser contida.

A sexualidade é, então, cuidadosamente encerrada. Muda-se para dentro de casa. A família conjugal a confisca. E absorve-a, inteiramente, na seriedade da função de reproduzir. Em torno do sexo, se cala. O casal, legítimo e procriador, dita a lei. Impõe-se como modelo, faz reinar a norma, detém a verdade, guarda o direito de falar, reservando-se o princípio do segredo. No espaço social, como no coração de cada moradia, um único lugar de sexualidade reconhecida, mas utilitário e fecundo: o quarto dos pais (FOUCAULT, 2017, pp. 7-8).

O sexo, a partir no século XVIII, diferentemente dos séculos anteriores, é interrogado pelo discurso científico. Isso quer dizer, que o sexo foi capturado por um mecanismo e posto em estreita vigilância. $\mathrm{O}$ sexo permitido centrava-se nas relações matrimoniais:

o dever conjugal, a capacidade de desempenhá-lo, a forma pela qual era cumprido, as exigências e as violências que o acompanhavam, as carícias inúteis ou indevidas às quais servia de pretexto, sua fecundidade ou a maneira empregada para torná-lo estéril, os momentos em que era solicitado (períodos perigosos da gravidez e da amamentação, tempos proibidos da Quaresma ou das abstinências), sua frequência ou raridade: era sobretudo isso que estava saturado de prescrições (FOUCAULT, 2017, p. 41).

Este sistema discursivo da monogamia heterossexual, alicerçava-se pela aliança legítima. Por outro lado, as sexualidades periféricas "povoavam os conselhos de disciplina, as casas de correção, as colônias penitenciárias, os tribunais e asilos" cujos estigmas classificavam-se em "loucura moral", "neurose genital", "aberração do sentido genésico", "degenerescência ou desequilíbrio psíquico" (FOUCAULT, 2017, p. 45). Segundo Foucault, a medicina penetra com grande aparato nos prazeres do casal inventando patologias orgânicas, funcionais ou mentais. A interdição e o controle 
higienizaram a família pela separação entre adultos e crianças, em cômodos singulares; pela segregação entre meninos e meninas; pela atenção sobre a sexualidade infantil e pela proibição da masturbação. Todavia, Foucault refuta a hipótese de maior repressão sobre o sexo nas sociedades industriais modernas. O que é posto em debate são os dispositivos que acionam uma vontade de saber sobre a sexualidade em estratégias de controle sobre os indivíduos e os seus corpos. $\mathrm{Na}$ Enciclopédia ilustrada da vida sexual, aconselha Magnus Hirschfeld ao futuro marido:

Existem, como todos sabem, mulheres que são frias até ao ponto de sentirem uma verdadeira repulsa por tudo o que concerne aos desejos sexuais, sem que isso as impeça de serem espôsas modelares, que cuidam do lar e amam platônicamente os maridos. Contra essa frigidez, pouca coisa pode ser feita. Mas, quando se trata de uma espôsa de apetites venéreos pronunciados, será conveniente incitá-la a seguir um tratamento para impedir que sua saúde se arruíne ou arruíne a do marido. A consulta médica, nesse caso, se torna necessária, da mesma forma que os banhos quentes muito prolongados; adotar-se-á também uma medicação sedativa apropriada, esforçando-se por diminuir o ardor da espôsa erótica (HIRSCHFELD, s/d, p. 251).

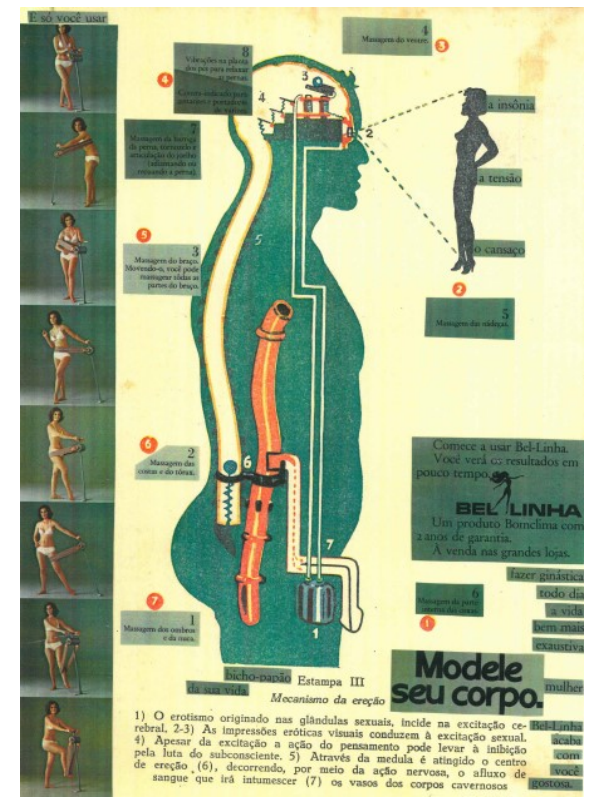

Figura 2: Fotomontagem da série Roupa de baixo, Bicho-papão, 2020. FONTE: Da autora

Magnus Hirschfeld explica a leitora da Enciclopédia ilustrada da vida sexual, pela numeração em vermelho, o mecanismo da ereção masculina, concentrados em exatos sete postos de estimulo:

1) $O$ erotismo originado nas glândulas, incide na excitação cerebral. 2-3) As impressões eróticas visuais conduzem à excitação sexual. 4) Apesar da excitação a ação do pensamento pode levar à inibição pela luta do subconsciente. 5) Através da medula é atingido o centro de ereção, 6) decorrendo, por meio da ação nervosa o afluxo de sangue que irá intumescer 7) os vasos dos corpos cavernosos. (HIRSCHFELD, Magnus. Enciclopédia ilustrada da vida sexual. S/D, p. 63)

De acordo com Foucault, a scientia sexualis operou, em nome das urgências biológicas e das normas médicas, imperativos de uma moral que qualifica a diferença entre a fisiologia da reprodução e a medicina da sexualidade. Nesse território opressor de prerrogativa masculina (branca) tanto a ciência quanto a política orientaram e legitimaram instrumentos do saber/poder 
implicando domínio e controle sobre a sexualidade feminina (corpo e libido) e sobre a produção intelectual, política e artística destas.

É visível, na narração visual de Magnus Hirschfeld a propósito da Enciclopédia ilustrada da vida sexual, o dimorfismo da libido sexual entre o corpo masculino culturalizado e a domesticação do corpo feminino. Ao primeiro é designada toda uma engrenagem mecânica de conotação ativa, lembrando os inventos da revolução industrial próprios de uma cultura científica de dominação. Ao segundo, o gênero feminino, não há estímulo aparente, leitura que nos conduz à passividade da mulher (esquema que a imagem reproduz pela estilização do corpo feminino), uma mímesis dos autômatos. A crítica feminista foi a primeira que apontou e analisou o vínculo entre natureza/cultura, mulher/homem:

A força com a qual o discurso feminista designou o corpo feminino como produto da história política, e não simplesmente da história natural, deve ser proclamada como o início de uma das maiores rupturas epistemológicas do século XX (PRECIADO, 2017. p.151).

$\mathrm{Na}$ fotomontagem Bicho-papão, uma paródia à antropofagia erótica masculina, a narrativa visual justapõe dois documentos de época, a didática ilustração da enciclopédia de Magnus Hirschfeld e a propaganda da Bel Linha que apresenta à leitora da revista Desfile, no ano de 1972, um dispositivo portátil para modelar o corpo. É curioso perceber que a performance da ginástica da usuária com o artefato Bel Linha se dá em roupas de baixo. Também é notável, que na capa dessa mesma revista, destinada ao público feminino, encontra-se enunciada a matéria "Simone de Beauvoir fala para você". O contexto brasileiro sinaliza a vagarosa apreensão da literatura feminista que é apenas divulgada em 1972, como manchete, entre as páginas coloridas das tendências francesas da moda que chegam ao espaço doméstico das damas brasileiras. Na seguinte edição da revista em questão, $\mathrm{n}^{\mathrm{o}} .31$ abril de 1972, na matéria de Alexandros Evremidis, lê-se:

a partir da II Grande Guerra, os meios de comunicação de massas, a erotização e a promoção dos valores femininos abriram certas brechas na estrutura, favorecendo o aparecimento de um certo tipo de mulher no Ocidente: o da mulher independente profissional e sexualmente. Grande foi, nesse período, a contribuição de Simone de Beauvoir através do seu livro $\mathbf{O}$ segundo Sexo, para a conscientização das mulheres. Mas nos países subdesenvolvidos, como no Brasil, a luta continuou sendo de uma elite pois o trabalho da mulher média é apenas auxiliar na economia da família (Revista Desfile, $\mathrm{n}^{\circ} .31$, Abril, 1972, p.118).

No livro A aventura de contar-se: feminismos, escrita de si e invenções da subjetividade, Margareth Rago indica, em 2013, após décadas de debate sobre causas feministas, que ainda está em pauta "técnicas e práticas de produção de si" como movimento "para libertar as mulheres da colonização de seus corpos e psiques" (2014, p. 26). A mesma autora, em 2002, lança a tese, no texto $O s$ mistérios do corpo feminino, ou as muitas descobertas do 'amor venéris', de que o clitóris, pequeno órgão do prazer feminino, física e discursivamente subjugou-se ao domínio do aparelho político, cujos regimes totalitários asseveraram restrições e controle sobre o corpo da mulher o qual se fechou como descoberta de si. Alexandros Evremidis, concluindo seu texto, dá seu diagnóstico sobre o perfil da mulher brasileira anunciando a fundamental importância do I Congresso de Mulheres que estava para acontecer, em 1972, no Rio de Janeiro:

A mulher brasileira - diz Heloneida Studart - ainda está no nível doméstico, limitando-se ao papel de mãe e dona-de-casa. A maioria, se solteira, ainda espera o véu-e-grinalda; se casada, sendo desajustada, traída ou infeliz, apela para candomblé e cartomantes ou, se puder pagar, para psiquiatras. O congresso mostrará que ela precisa participar mais da vida econômica e cultural do país. É um absurdo que num país em que as mulheres são $50,4 \%$ da população, o trabalho feminino perfaça apenas $17 \%$. No campo de instrução universitária, as mulheres não representam 
mais do que $1 \%$ da população feminina. Muita coisa terá que mudar depois do congresso (Revista Desfile, n $^{\circ}$.31, Abril, 1972, p.120).

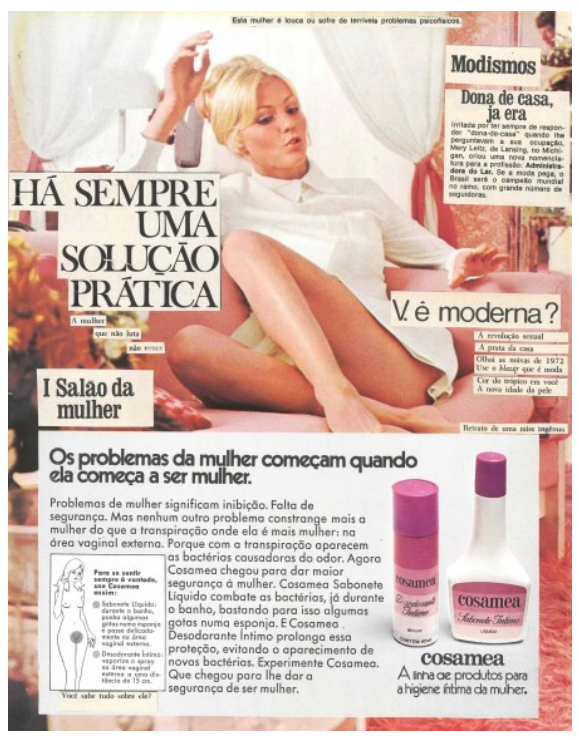

Figura 3: Fotomontagem da série Roupa de baixo, Coisa minha, 2020. FONTE: Da autora

$\mathrm{Na}$ contra capa da revista, na qual se encontra a matéria de Alexandros Evremidis, está o moderno sabonete líquido íntimo que sublinha: "os problemas da mulher começam quando ela começa a ser mulher". A menção é clara às brasileiras: ter consciência do seu próprio corpo e sua intimidade, mas também, ao se referir ao contexto temático da revista, acordar para o necessário engajamento político, já fomentado na França e nos Estados Unidos, a proposito do I Congresso de Mulheres. Ressalta Evremidis que

no Brasil, os movimentos feministas praticamente não existem. Várias tentativas de conscientização da mulher brasileira fracassaram porque 'as líderes são muito individualista e as massas sem estrutura'. O que há são organizações feministas festivas que mais se preocupam com a escolha 'das dez mais do ano' e jantares de confraternização do que com o feminismo propriamente dito. Abdicando à luta pelos direitos das mulheres, dedicam-se à caridade e à assistência social. Sente-se uma inércia que retarda cada vez mais a emancipação. Foi essa a imagem que Bety Friedan levou do Brasil em maio do ano passado. Analisando sua viagem em artigo publicado no número de outubro da revista Redbook, considerou-a um 'excelente aprendizado': 'Pensei que a situação da mulher era difícil nos EUA mas agora acho que é ótima, comparada à da mulher brasileira' (Revista Desfile, ${ }^{\circ} .31$, Abril, 1972, p.120).

Vale lembrar que estávamos sob árduo regime militar pós-golpe de 1964. Roberta Barros (2016, p.12) apresenta sua tese sobre o feminismo brasileiro, na qual defende que o movimento imprimiuse no Brasil com outras características. Menos centrado nos temas como a liberdade sexual, o direito ao aborto e ao divórcio, a contenda das mulheres brasileiras deu-se pela militância e resistência potencializando o espaço doméstico da família ameaçado pela violência do Estado. 


\section{O corpo modelado em branco}

Simone de Beauvoir abre o capítulo A mulher casada afirmando que:

O destino que a sociedade propõe tradicionalmente à mulher é o casamento. Em sua maioria, ainda hoje, as mulheres são casadas, ou foram, ou se preparam para sê-lo, ou sofrem por não sê-lo. É em relação ao casamento que se define a celibatária, sinta-se ela frustrada, revoltada ou mesmo indiferente ante essa instituição (2016, vol.2. p. 185)

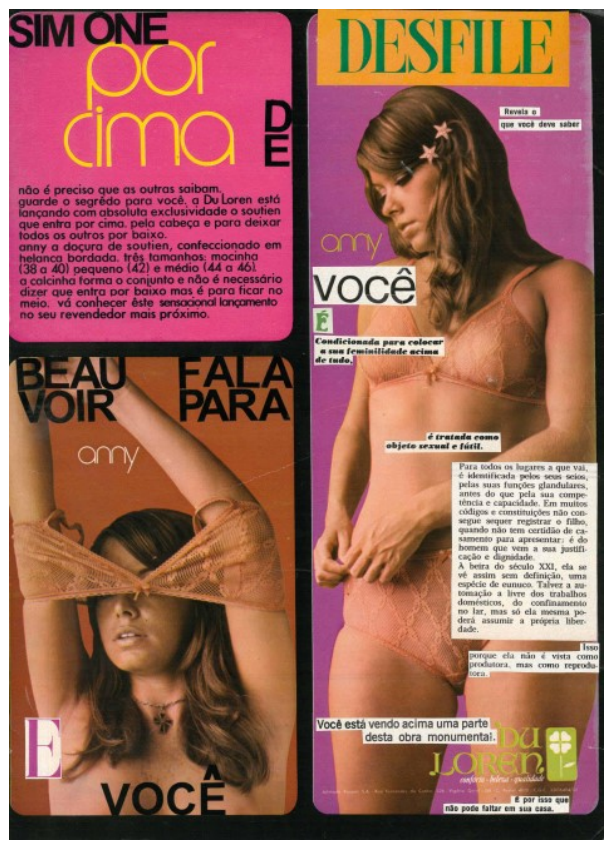

Figura 4: Fotomontagem da série Roupa de baixo, Sim(one) Beau(voir) fala por cima, 2020. FONTE: Da autora

Beauvoir publica $O$ segundo sexo em 1949, portanto, segunda metade do século XX, momento histórico que, assombrosamente, ainda alastra as teses iluministas do século XVIII sobre a natureza do sexo feminino e sua desigualdade jurídica e social frente ao sexo masculino. Observa a filósofa e ativista política que as mulheres, apesar de lutarem contra o mito da feminilidade e de começarem a firmar concretamente sua independência, ainda não conseguem viver integralmente sua condição de ser humano. Ao que se deve essa gravíssima desigualdade que impede a mulher de acionar os direitos universais, declarados em 1789, que garantem que todos os homens são por natureza iguais? Certamente, parte desse pensamento cristalizado, deve-se à função formadora ou deformadora da educação, segundo afirma Michèle Crampe-Casnabet, diferentes para homens e mulheres. Diz a historiadora, que "a natureza do ser humano já não pode ser definida apenas em termos de essência, mas sempre e ao mesmo tempo em termos de instituição e de história" (1991, p. 395). Beauvoir salienta que ao serem educadas por mulheres e circunscritas ao mundo feminino, o destino normal para as mulheres é o casamento, que as subordina ao homem, pois o "prestígio viril está longe de se ter apagado: assenta ainda em sólidas bases econômicas e sociais" (BEAUVOIR, 2016, vol. 2, introdução).

Michèle Crampe-Casnabet faz uma longa revisão historiográfica sobre as obtusas ideias educacionais no século das luzes, afirmando que "a mulher é um objeto de representação constituído por um outro sujeito, diferentemente do seu, que se coloca no seu lugar, o sujeito masculino" (1991, p. 370). Portanto, o discurso iluminista, século XVIII, que se assenta filosoficamente eliminando as diferenças de raça e de sexo, é um discurso do homem e para o 
homem. Apesar de seu esclarecimento, justifica a inferioridade da mulher, uma vez que, ela é vítima dos impulsos irracionais do seu sexo. Pergunta a historiadora, em meio a uma dificultosa engrenagem teórica acionada por filósofos e escritores - Rousseau escreveu Émile ou De l'éducation (quatro livros dedicados a educação masculina) e Sophie ou la Femme (quinto livro dedicado à educação da mulher); D'Alembert e Diderot dedicaram-se ao artigo Femme, na Encyclopédie, estritamente amparados pela anatomia e fisiologia do naturalista Buffon - "quem pode definir a mulher se lhe é recusada a possibilidade de se definir a si própria? E como, de que ponto de vista, se poderá defini-la?" (CRAMPE-CASNABET, 1991, p. 370). Beauvoir, no século $\mathrm{XX}$, afirma que

ninguém nasce mulher: torna-se mulher. Nenhum destino biológico, psíquico, econômico define a forma que a fêmea humana assume no seio da sociedade; é o conjunto da civilização que elabora esse produto intermediário entre o macho e o castrado, que qualificam de feminino (2016, vol.2. p. 11).

A educação respeita as concepções binárias alicerçadas pela ciência biológica, e portanto, as pessoas de cada sexo são educadas diferentemente. O princípio da igualdade dos direitos é violado pela soberania de um dos sexos no casamento, o masculino sobrepujando o feminino. Poulain de la Barre, em 1673, publica De l'égalités des deux sexes, no qual diz que a anatomia revela diferenças, todavia, nada indica que um sexo deva-se subjugar-se inferior ao outro. Assinala-se uma fundamental desigualdade pedagógica entre os sexos, em que as diferenças de natureza e de comportamento, impedem as mulheres de progressos nas ciências e nas artes. Helvéticus em $D e$ l'Esprit, 1758, manifesta que a igualdade não se fundamenta nos direitos naturais, mas pelo espírito. Portanto, homens e mulheres, em condições normais, têm a mesma capacidade cerebral e física de ascender pensamentos elevados (CRAMPE-CASNABET, 1991, p. 397).

Esclarece Laqueur (2001, pp. 252, 263 e 254) que "as demandas políticas para a criação de sexos biologicamente distintos e o papel específico da ciência nesse empreendimento são especialmente claros no final do século XIX". Afirma que o papel da fisiologia era fundamental pois o progresso cultural, diante do comportamento moral, deveria ser garantido pelas gerações sucessoras cujos hábitos individuais encarnavam-se como segunda natureza do corpo. "Qualquer coisa que se pensasse sobre a mulher e seu lugar de direito no mundo podia ser compreendido em termos de corpos incessantemente abertos às demandas interpretativas da cultura". A relação com o prazer também se definiu por um processo de diferenciação entre os sexos: "o desejo tinha uma história e o corpo feminino era distinguido do masculino, à medida que as grandes transformações da sociedade europeia entre os séculos XVII e XIX faziam uma pressão insuportável contra as antigas visões do corpo e de seus prazeres" que eram menos normativos.

Apesar de o casamento se fundar em contrato, cujo acordo é reciprocamente voluntário, as convenções civis estabelecem a subordinação feminina pelo sexo masculino. Portanto, ao se casar, a mulher passa a uma servidão doméstica voluntária, aceita na convenção matrimonial estabelecida, estranhamente contraditória à ideia de igualdade. O papel social da mulher define-se pela constituição frágil de sua anatomia, ser esposa; e pela funcionalidade natural de seu sistema biológico, ser mãe.

Minha mãe empreendeu uma escola de bordado à máquina e nas horas silenciosas bordava enxovais matrimoniais. Treze anos separam a data de casamento de meus genitores da publicação de $O$ segundo sexo de Simone de Beauvoir. Antes de seu casamento minha mãe já tinha ornado, desde os onze anos de idade, o seu sistemático enxoval que se relaciona com as diárias ocupações e preocupações de uma 'mulher do lar'. Falar do bordado e de sua grafia é, portanto, reconstruir e ativar o regresso à casa de meus genitores, espaço doméstico de minha educação sexual numa cidade interiorana no oeste catarinense. 
Desarmar o enxoval matrimonial como prática artística possibilita uma grafia que opera simultaneamente a revisão crítica sobre a educação doméstica feminina a partir de textos enciclopédicos, manuais pedagógicos, colunas de jornais e revistas femininas publicadas no Brasil por volta dos anos de 1960, 1970 e 1980, período que coincide com o casamento de minha mãe, meu nascimento e o início dos bordados maternais à coleção do meu enxoval matrimonial.

Recordo-me, desde muito pequena, de minha mãe, em sua grande mesa laboriosa, atenta nesse ofício moroso que é o de bordar: desfiando fazendas de linho para feitura do crivo; tencionando a cambraia no bastidor para a feitura dos acordoados, dos bordados a relevo, do festonnet e do bordado à inglesa; desenhando com fino traço os motivos de flores sobre os tecidos delicados como o voil e o organdi que dariam suporte ao encaixe renascença, ao bordado rococó e ao richelieu; escrevendo os monogramas nos lenços, almofadas, travesseiros e lençóis. Um modus operandi singular que assegurava, pelas mãos de minha mãe, a memória de uma prática feminina legada por gerações à filha mais velha. E entre tecidos, linhas e objetos de armarinho, eu e as minhas duas irmãs crescíamos junto com a escrita de nossos enxovais. No roupeiro, os sabonetes decorados exalavam fragrâncias entre as caixas que se acumulavam vultuosamente para acomodar os artefatos colecionados por mãe, avó e tias e destinados ao longínquo casamento das três fillhas.

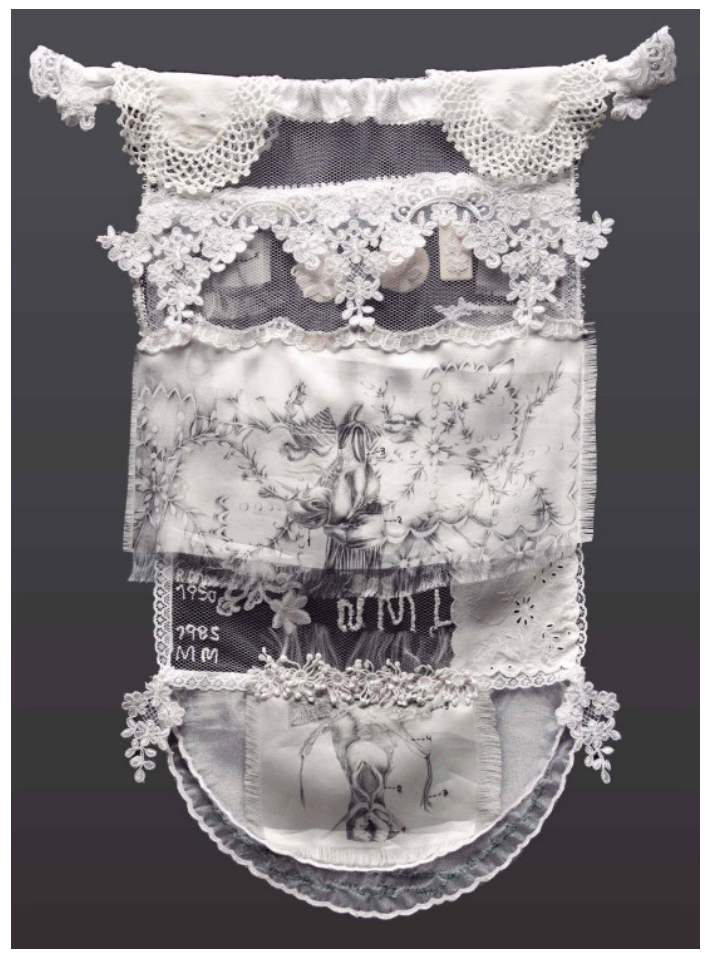

Figura 5: Série de bordados segunda Lição Enciclopédica, bordado à Inglesa. Desenho/objeto sobre filó. Grafite sobre gazar de seda e apropriação de bordados feitos à máquina do enxoval maternal. 2019. FONTE: Da autora

Essa tradicional sintaxe ornada, o bordado à Inglesa, que toma do substrato branco o corpo têxtil necessário ao branco do bordado, é a terceira lição do Livro Singer, usualmente destinada aos enxovais de casamentos e de recém-nascidos. A técnica envolve dois procedimentos de recorte e cheio. Vaza-se o tecido do interior de cada ilhozinho (pequenos furos) e acordoa-se as beiradas, seguido do ponto real, que dá o relevo, ao motivo bordado. O dispositivo do bordado acima descrito, em sua capacidade de ser vazio e cheio, é literalmente adjetivo destinado às representações do útero. $\mathrm{O}$ tema dessa lição reporta-se às ilustrações anatômicas do sexo feminino em comparação ao masculino. É importante frisar que a estética da diferença anatômica sublinhou a necessidade de uma ciência taxionômica ávida por nomear, distinguir, particularizar e classificar. Até o final do 
século XVII era possível observar nos mapas anatômicos que os ovários eram nomeados como "pedras femininas" ou "testículo feminino, o clitóris como "pênis feminino", os "canais deferentes" como trompas de Falópio e a vagina como "bainha do ventre" (LAQUEUR, 2001, pp. 197-8). Descreve o autor que a palavra vagina, que designa a bainha ou órgão côncavo, será vernaculizada nas línguas europeias por volta de 1700. Antes disso, não houve a necessidade de nomear o dimorfismo sexual. O enfoque seletivo dessa epistemologia biológica, da diferença entre os sexos apregoada pelo iluminismo, representou o corpo feminino a partir de sua diferenciação do masculino, portanto, o útero é um saco oco cuja única função reserva-se à reprodução: "encontra-se o útero ou matriz, que é um saco ôco, de paredes grossas e contrácteis, situado entre a bexiga e o reto (última porção do intestino). Êste órgão é destinado a alojar o óvulo durante tôda a sua evolução e a botá-lo fora, no parto" (HIRSCHFELD, s/d, p. 24).

\section{Nos debaixos está o corpo}

Louise Bourgeois desconstrói o paradigma da casa como lugar diurno e seguro. Propõe celas com guilhotinas, cantos escuros, quinas que interditam o lugar assegurado do sexo: “Toujours sur le métier replace ton ouvrage"' (Sempre põe tua obra de volta no tear, tradução nossa) (BOURGEOIS apud VERHAEGHE, 2011, p. 111). Dos fios de aracne de Louise ao ponto desfeito de Penélope tem-se a agulha que fere para bordar, todas são estratégias do tramar/persuadir/sabotar. A tékhne do bordado assegura-se pela experiência de uma habilidade háptica que se inscreve entre o fincar da agulha e o laçar da linha ao arremate do nó, cada ponto, que pressupõe o furo e a laçada do bordado, tensiona na grafia do ornato certa violência. Pensar os debaixos da educação sexual feminina é expor em quais dobras e nós, do constructo sociocultural da educação feminina, ocultaram-se experiências silenciosas.

Debaixo significa ao mesmo tempo o esconderijo do que está escondido e do que está escondendo, de um lado, do que permanece escondido no fundo, ou mesmo no sem-fundo ou no bas-fond (escondido embaixo, enfiado debaixo, guardado, salvo ou inumado debaixo de um subsolo, de um envasamento, ou de um jazigo), e, de outro lado, do que se esconde, não na profundidade de um fundo, ou de um fundamento, mas na superfície de uma superfície ( DERRIDA, 2012, p. 283).

Trata-se, como afere Jacques Derrida, dos lugares e da topografia relacionada com os debaixos (les dessous como substantivo e par dessous e en dessous como advérbio) do suporte. Tanto aquilo que se pode nominar (a natureza feminina e seu sexo) quanto aquilo que se pode localizar (o lugar de sua presença). Assumem aqui, pela enciclopédia sexual e o livro do bordado, o eixo paradigmático do significante/significado, em um modelo normativo que se seguiu mais detidamente a partir da scientia sexualis que definiu, para homens e mulheres, conforme a compreensão foucaultiana, os modelos de sujeição.

Pode-se supor, portanto, que não há leito cristalino (nos lençóis, lenços, fronhas, anáguas, roupas íntimas, vestido de noiva, cortinas) da experiência feminina quando o corpo da mulher é tomado como campo disciplinar. É no debaixo que Derrida reconhece o subjétil ${ }^{5}$, conceito/palavra rara,

\footnotetext{
${ }^{5}$ Explica Derrida, que o parergon (moldura) e o subjétil (suporte), frequentemente negligenciados, foram deixados em segundo plano, e seguiram ignorados, desconhecidos, recalcados, denegados. "Um subjétil parece intraduzível, observese o axioma, ele organiza o corpo-a-corpo com Artaud. Com isso duas coisas podem ser entendidas. Por um lado a palavra 'subjétil' não permite tradução. Com toda a sua parentela semântica ou formal, de subjetivo a tátil, de subposto, suporte ou súcubo a projétil etc., ela jamais atravessará a fronteira da língua francesa. Por outro lado, um subjétil, ou seja, o suporte, a superfície ou o material, o corpo único da obra em seu primeiro acontecimento, no nascimento, aquilo que não se deixa repetir, aquilo que se distingue tanto da forma quanto do sentido e da representação, também desafia a
} 
intraduzível, que o filósofo a toma de Antonin Artaud enquanto aquilo e naquilo que se fez surgir dos/nos debaixos da memória (DERRIDA, 2012, p. 287). Memória da matéria que "designa o que está de certo modo deitado embaixo (sub-jectum) como substância, um sujeito ou um súcubo" (DERRIDA, 1998, p. 26).

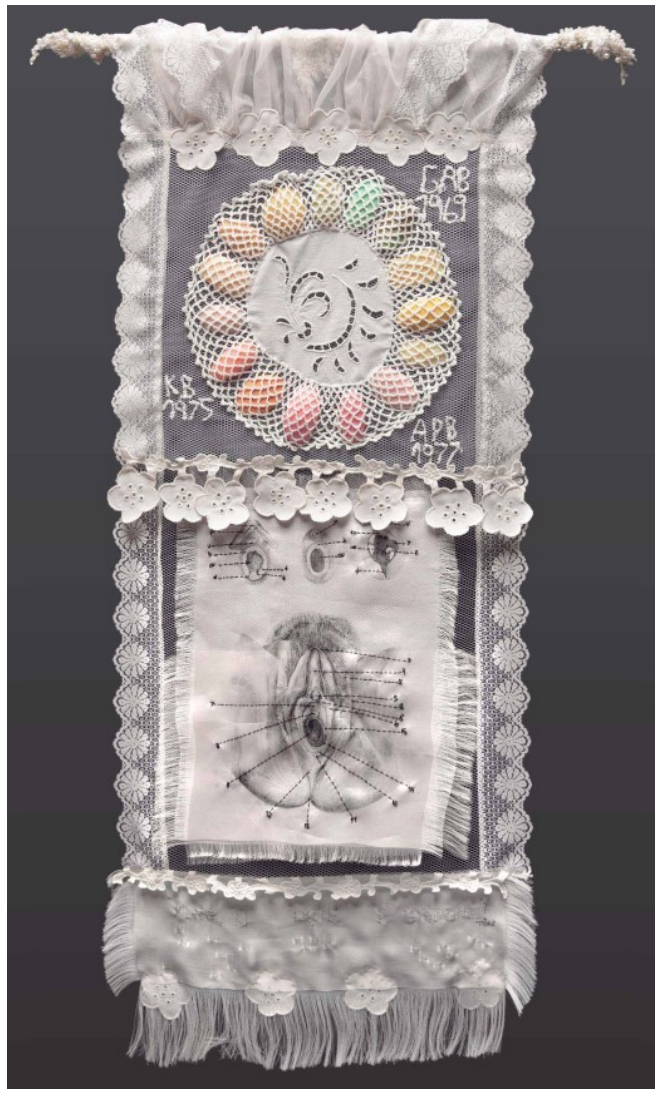

Figura 6: Série de bordados quarta Lição Enciclopédica, bordado Richelieu. Desenho/objeto sobre filó. Grafite sobre gazar de seda e apropriação de bordados feitos à máquina. 2019. FONTE: Da autora

Esse ornato Richelieu traz a urgência de uma regra, indicada logo no início do manual de bordado Singer, leva em consideração a destreza dos movimentos de ambas as mãos, no manejo do bastidor, à feitura das linhas curvas e dos ângulos nos acordoados que dão moldura ao furo feito no tecido. $\mathrm{O}$ acordoado é uma técnica que consiste em cobrir, com pontos juntos, a meada que cinge o rasgo, de modo a ficar um cordão liso. Portanto, uma técnica de encobrimento. O bordado Richelieu pressupõe duas importantes operações, abertura e cobertura.

Toda vez que me deparo com a imagem de Gustav Courbet, aquela que diz ser o sexo feminino a origem, examino-a em seu defloramento. De certo deve ser esse aspecto, de não virgem, que a manteve tão escondida aos olhos ou deve ter sido a causa do rasgo felpudo cujo olho recortado nos mira. Quem sabe foi o incômodo advindo dessa falta, uma falha, acionada nessa bainha operante (a vagina) que apreendeu a percepção de Lacan. Nunca estive diante da pintura L'origine du monde, e dela não tenho o que narrar, mas já estive no front de minha própria origem, quando vi minha mãe, de pernas alargadas, disposta na table ginecológica. O bordado Richelieu é ornato de trincheiras

tradução. Nunca será transportado para outra língua. (...) A palavra ‘subjétil' é ela mesma um subjétil” (DERRIDA, 1998, p. 29). 
abertas, da fenda que se abre, no ato da defloração do subjétil da matéria, à gênese do seu acontecimento como experiência intraduzível, irrepetível, irreversível. A quarta lição em Richelieu foi a tentativa de fazer um Courbet feminino quando, de minha experiência original, posicionei-me no olho do furacão. É interessante observar que na enciclopédia da vida sexual de Hirschfeld há pênis ereto, mas não há vulvas defloradas. Tratei então de adicionar à imagem enciclopédica (aquela que no livro ilustra-se como vulva), não deflorada na sua experiência sexual de origem, a perda gráfica do hímen. Uma operação necessária à lição ornada do Richelieu, que ao meu ver é bordado que se inscreve pelas profundezas, assim como as pinturas de Courbet, onde a natureza, posta nua, é anterior à ciência civilizatória, e por isso, é cortante, vertiginosa, opulenta, não recalcada.

O subjétil é, igualmente, posto na ordem investigativa de Georges Didi-Huberman em pelo menos dois livros, Diante da Imagem e A pintura encarnada. No primeiro, o autor diz ser o subjétil aquilo que se opõe a palavra sujet que é empregada nos textos iconográficos panofskyanos como objeto da mímesis, o motivo, o representado. Segundo Didi-Huberman "isso permite justamente ignorar tanto os efeitos de enunciação (em suma, de fantasma, de posição subjetiva) quanto os efeitos de jet [jato, vigor], de subjetilidade (em suma, de matéria) com que a pintura eminentemente trabalha - e faz questão de trabalhar" (2013, p. 307). Didi-Huberman fala a propósito da causa material da pintura que menos descreve e mais apresenta a matéria do desejo. Sedimenta-se em rastros, acidentes soberanos, fulguração de substância, cor sem limite regulado e que se opõe a toda mímesis. É trama, desfiamento insensato de pintura, expõe o sintoma, aquilo que ameaça todas as certezas; é o fantasma que sobrevém. Como acidente da representação entrega-se ao risco da matéria "e assim, sua intensidade pictórica tende a desfazer a coerência mimética" a de não se assemelhar (2013, p. 332).

Entendo que o subjétil da educação sexual feminina (o espaço doméstico no qual foi encerrada a mulher e a representação do seu corpo ao qual foi submetida), superfície não mimética (a qual sempre foi a pretensa científica do dimorfismo sexual), ameaça tudo o que sempre se averbou pela scientia sexualis. O subjétil feminino expõe o sintoma da sujeição dos corpos dóceis produzidos pelas normativas disciplinares (aquilo que na superfície se esconde por ser velado e disciplinado), mas também, o recalque da libido que se encontra no bas-fond, aqui definido como fulguração da matéria do desejo.

A verdadeira competência do acontecimento do subjétil nesse texto é armar a grafia do bordado nos intrínsecos movimentos de estar sob e sobre. É suporte/superfície/corpo que permite construir uma epistemologia crítica partindo de uma topografia arqueológica (o substrato entendido em seus acidentes), cujas ações voltam-se ao escavar, revolver, virar, sacudir, arejar os panos domésticos. É nos debaixos do subsolo, nas relações familiares, que estão escondidas as experiências femininas da intimidade, guardadas no esconderijo do silêncio que abriga também a impotência da fala e da escuta no diálogo entre mãe e filha. Esse debaixo esconde o prazer feminino obliterado nas práticas disciplinares (pedagógicas e comportamentais) que outorgaram à mulher um lugar definido nas estruturas sociais. Na nota de Marcelo Jacques de Moraes, tradutor do texto Os debaixos da pintura, da escrita e do desenho: suporte, substância, sujeito, sequaz e suplício, de Jacques Derrida, encontra-se a passagem que tomo por referência: "mas é evidente que Derrida vai explorar sobretudo a dimensão topológica geral que metaforiza sempre o baixo, o oculto, o invisível e, especialmente, o erótico, uma vez que remete diretamente ao sentido de "roupas de baixo" (MORAES apud DERRIDA, 2012, p. 280). São esses debaixos (les dessous, par dessous e en dessous) tomados politicamente por artistas mulheres, engajadas ao não engajadas ao feminismo, que confrontam os modelos de sujeição (enunciados binários, práticas sexuais falocêntricas). São políticas do corpo e práticas de si conforme diz Foucault, e que para Luana Saturnino Tvardovskas ativam "novas configurações dos prazeres e uma multiplicidade de práticas e saberes produzidos pelos corpos" (2015, p. 40). 
Numa atenta revisão da ciência médica e biológica, Thomas Laqueur confirma que o orgasmo, propriedade comum entre mulheres e homens até o século XVII, passa a ser interpretado diferentemente entre dois sexos, feminino e masculino. Diz o historiador que o prazer feminino foi suprimido dos relatórios médicos sobre o tema da concepção, no momento em que se estabeleceu a diferença fisiológica e funcional do corpo feminino em relação ao corpo masculino. O corpo da mulher definiu-se exclusivamente pela biologia reprodutiva deixando o orgasmo feminino de ser relevante à fecundação. Se a descoberta do clitóris deve-se a Readolus Columbus em 1559, atesta Laqueur que Freud, em 1905, redescobre em plena amnésia do século XX o orgasmo clitoridiano. A que se deve esse esquecimento de quase três séculos? São essas inquietações, respaldadas na Enciclopédia Ilustrada da Vida Sexual de Magnus Hirschfeld e no Livro de Bordado Singer, que acompanham a minha prática artística.

\section{Considerações}

Folhear o antigo livro, de 1947, das lições de bordado que alfabetizou minha mãe em seu ofício de bordadeira (legado de minha vó) e aproximá-lo da sua coleção de bordados domésticos, é pensar no trousseau de mariage como elemento disciplinar da educação sexual feminina. Mas também, é pensar o bordado como engatilho às urgências do presente nas práticas artísticas feministas. Tudo isso, quando posto ao lado das pedagogias sexuais, como no caso da enciclopédia de Magnus Hirschfeld, é ação de desmonte, como fora dito anteriormente, que ativa - como se pode comprovar na historiografia da arte latina americana, pós década de 1960 - sobrevidas das práticas domésticas femininas que, para além de denunciarem modos de opressão, acionam, como enfatiza Margareth Rago, modos de sentir e outras possibilidades de experiência libertária ao pensamento crítico e ético.

Trago Didi-Huberman (2015) que articula o passado como tarefa da recordação tal qual o fez Benjamin. Para Didi-Huberman, os rastros sobrevêm do inconsciente do tempo, identificado pela expressão l'insu, ou seja, o saber que não se sabe, o saber que não foi tomado pelo consciente e que é o tempo recalcado da história. Recupero a ideia do autor que diz ser os rastros (fragmentos, escombros, restos, vestígios) contrapontos, quedas, irrupções, contrarritmo, sintomas, mal-estar. A renúncia hierarquizante das certezas e dos regimes de verdades dá-se através dos fragmentos atualizados no presente histórico, como um trabalho de bricoleur ou de bordadeira. É nessa perspectiva, de acionar a potência do fragmento na atualidade, que Didi-Huberman reconhece na sobrevivência (Nachleben) - conceito que compartilha de Warburg - o resíduo, o resto e o rastro com os quais a latência de uma crise é exposta, e portanto, é diagnóstico do retorno do recalque.

Pois bem, Benjamin nos situa também: "toda experiência profunda deseja, insaciavelmente, até o fim de todas as coisas, repetição e retorno, restauração de uma situação original, que foi seu ponto de partida" (BENJAMIN, 1985, p. 253). Ponderando a complexidade do acima exposto, acredito, sem implicar em reducionismo, que esse é o labor carregado por gerações de mulheres artistas. O resíduo mnemônico sobrevém pelo subjétil, frente ao que não pode ser substituído no passado da experiência, mas que, através da repetição e do retorno, como locus de resistência aciona novos modos de constituição de subjetividades na arte contemporânea através da autobiografia, de espaços de discursividade e do agenciamento da memória.

Mas afinal, qual é o ponto de partida na impossibilidade da restauração de uma situação inicial? É, portanto, numa espécie de inquietude que encontro nos debaixos das lições de bordado, uma clave para articular a sobrevivência de estruturas narrativas da subjetividade feminina que, através da grafia do bordado, revolve as camadas do silêncio recalcadas nos debaixos da educação, isto é, o subjétil no qual se esconde o erotismo feminino obliterado pelas práticas normativas históricas. Pergunta Derrida: "o debaixo, na hierarquia de uma topologia, pode ser o inferior, mas pode 
também ter o valor superior da fundação ou do fundamento ao fazer, pensar ou dizer alguma coisa. O que é, então, que todos esses debaixos podem, assim, parir, assujeitar, mas também oferecer recusando, exibir ocultando?" (2012, p. 284).

Empreendo uma tomada de ação prática da memória necessária para rever os discursos pedagógicos cristãos, fisiológicos, médicos, ditatoriais que institucionalizaram regimes de verdade sobre o feminino, a respeito do sexo/corpo e da educação/comportamento. Acredito que a 'efetiva' educação feminina (aquela dos regimentos disciplinares) se deu através da renúncia do sujeito de prazer. $\mathrm{O}$ agenciamento dessa memória de atividade reatualizada na formação do sujeito feminino crítico é a matriz dos discursos verdadeiros, a parrhesía (a fala franca e de risco necessária ao dizer verdadeiro), em permanente transformação nas práticas de si da arte contemporânea.

\section{Referências}

BARROS, Roberta. Roberta Barros. [Elogio ao toque ou como falar de arte feminista à brasileira]. Rio de Janeiro: Ed. Do Autor, 2016.

BARTHES, Roland. O prazer do texto. São Paulo: Perspectiva, 2008.

. O rumor da língua. São Paulo: Martins Fontes, 2004.

BEAUVOIR, Simone de. O segundo sexo: fatos e mitos. Vol. I. $3^{\text {a }}$. Edição. Rio de Janeiro: Nova Fronteira, 2016. 2016.

. O segundo sexo: a experiência vivida. Vol. II. $3^{\text {a }}$. Edição. Rio de Janeiro: Nova Fronteira,

BENJAMIN, Walter. A tarefa do tradutor, de Walter Benjamin: quatro traduções para o português. Lucia Castello Branco (org.). Belo Horizonte: Fale/UFMG, 2008.

2006.

. Passagens. Belo Horizonte: UFMG; São Paulo: Imprensa Oficial do Estado de São Paulo,

. Rua de mão única. Obras Escolhidas II. 5 ed. São Paulo: Brasiliense, 1995.

BLANCHOT, Maurice. A conversa infinita. São Paulo: Escuta, 2010.

BOURGEOIS, Louise. Louise Bourgeois: o retorno do desejo proibido. Curador Philip LarrattSmith; textos, Elisabeth Bronfen ... et al.; São Paulo: Instituto Tomie Ohtake, 2011.

BUTLER, Judith. Corpos que importam. São Paulo: n-1 edições; Crocodilo Edições, 2019.

CRAMPE-CASNABET, Michèle. "A mulher no pensamento filosófico do século XVIII". In: DUBY, Georges; PERROT, Michelle. História das mulheres no ocidente. Volume 3. Porto: Edições Afrontamento. São Paulo: Ebradil, 1991.

DERRIDA, Jacques. Enlouquecer o Subjétil. São Paulo: Ateliê Editorial: Fundação Editora da Unesp, 1998.

. Mal de arquivo: uma impressão freudiana. Rio de Janeiro: Relume Dumará, 2001.

$\overline{\mathrm{UFSC}} 2012$.

Pensar em não ver: escritos sobre as artes do visível (1979-2004). Florianópolis: Ed. Da

DELEUZE, Gilles. Diferença e repetição. Rio de Janeiro: Graal, 1988.

DESFILE. Revista Desfile. Rio de Janeiro: Bloch Editores S.A. $\mathrm{n}^{\mathrm{o}}$ 30, Março, 1972; $\mathrm{n}^{\mathrm{o}}$ 31, Abril, 1972. 
DIDI-HUBERMAN, Georges. Atlas, ou, O gaio saber inquieto. Belo Horizonte: Editora UFMG, 2018.

. A imagem sobrevivente: história da arte e tempo dos fantasmas segundo Aby Warburg. Rio de Janeiro: Contraponto, 2013.

. A pintura encarnada. São Paulo: Escuta, 2012.

34, 2013.

Diante da imagem: questão colocada aos fins de uma história da arte. São Paulo: Editora

. Diante do tempo: história da arte e anacronismo das imagens. Belo Horizonte: Editora UFMG, 2015.

DUBY, Georges; PERROT, Michelle. História das mulheres no ocidente. Porto: Edições Afrontamento. São Paulo: Ebradil, 1991.

FOUCAULT, Michel. A hermenêutica do sujeito: curso dado no Collège de France (1981-1982). $3^{\mathrm{a}}$. Edição. São Paulo: Editora WMF Martins Fontes, 2010. Fontes, 1990.

As palavras e as coisas: uma arqueologia das ciências humanas. São Paulo: Martins

. Problematização do sujeito: psicologia, psiquiatria e psicanálise. Ditos e Escritos, volume I. Rio de Janeiro: Forense Universitária, 2006.

Ética, sexualidade, política. Ditos e Escritos, volume V. Rio de Janeiro: Forense Universitária, 2017a.

. História da sexualidade I: a vontade de saber. 6 ${ }^{\mathrm{a}}$. Ed. Rio de Janeiro: Paz \& Terra, 2017b.

HIRSCHFELD, Magnus. Enciclopédia da Vida Sexual. 4a. Edição ampliada. Volumes 1 e 2. Rio de Janeiro: Edições Spiker, s/d.

HISTÓRIAS DA SEXUALIDADE: ANTOLOGIA. São Paulo: MASP, 2017.

HISTÓRIAS DA SEXUALIDADE. Catálogo da exposição. Curadoria de Adriano Pedrosa [et al.]; organização, Adriano Pedrosa, Camila Bechelany. São Paulo: MASP, 2017.

LAQUEUR, Thomas. Inventando o sexo: corpo e gênero dos gregos a Freud. Rio de Janeiro: Relume Dumará, 2001.

LIVRO BRASILEIRO DE BORDADOS SINGER. Quarta edição. Rio de Janeiro: Escola Nacional de Belas Artes; Biblioteca Nacional, 1947.

MULHERES RADICAIS: ARTE LATINO-AMERICANA, 1965-1985. Catálogo da exposição. Curadoria e textos de Cecilia Fajardo-Hill, Andrea Giunta. São Paulo: Pinacoteca de São Paulo, 2018.

PERROT, Michelle. História dos quartos. São Paulo: Paz e Terra, 2011.

. Minha história das mulheres. $2^{\mathrm{a}}$. edição. São Paulo: Contexto, 2017.

. "Os silêncios do corpo da mulher" In: MATOS, Maria Izilda Santos; SOIHET, Rachel. $O$ corpo feminino. São Paulo: Editora UNESP, 2003.

PINSKY, Carla Bassanezi; PEDRO, Joana Maria. Nova história das mulheres. São Paulo: Contexto, 2012.

PRECIADO, Paul B. (Beatriz). Manifesto contrassexual. São Paulo: n-1 edições, 2017.

RAGO, Margareth. A aventura de contar-se: feminismos, escrita de si e invenções da subjetividade. Campinas, São Paulo: Editora da Unicamp, 2013. 
Os mistérios do corpo feminino, ou as muitas descobertas do "amor venéris". Proj. História, São Paulo, v. 25, p. 181-195, dez. 2002.

ROVERE, Maxime (org.). Arqueofeminismo: mulheres filosóficas e filósofos feministas. São Paulo: n-1 edições, 2019.

TVARDOVSKAS, Luana Saturnino. Dramatização dos corpos: arte contemporânea e crítica feminista no Brasil e na Argentina. São Paulo: Intermeios, 2015. 